\title{
Quantification of Sunscreen Ethylhexyl Triazone in Topical Skin-Care Products by Normal-Phase TLC/Densitometry
}

\author{
Anna W. Sobanska and Jaroslaw Pyzowski \\ Department of Analytical Chemistry, Medical University of Lodz, Ulica Muszynskiego 1, 90-151 Lodz, Poland \\ Correspondence should be addressed to Anna W. Sobanska, a.sob@poczta.onet.pl
}

Received 14 October 2011; Accepted 8 December 2011

Academic Editor: Samuel Carda-Broch

Copyright () 2012 A. W. Sobanska and J. Pyzowski. This is an open access article distributed under the Creative Commons Attribution License, which permits unrestricted use, distribution, and reproduction in any medium, provided the original work is properly cited.

\begin{abstract}
Ethylhexyl triazone (ET) was separated from other sunscreens such as avobenzone, octocrylene, octyl methoxycinnamate, and diethylamino hydroxybenzoyl hexyl benzoate and from parabens by normal-phase HPTLC on silica gel 60 as stationary phase. Two mobile phases were particularly effective: (A) cyclohexane-diethyl ether $1: 1(\mathrm{v} / \mathrm{v})$ and (B) cyclohexane-diethyl ether-acetone $15: 1: 2(\mathrm{v} / \mathrm{v} / \mathrm{v})$ since apart from ET analysis they facilitated separation and quantification of other sunscreens present in the formulations. Densitometric scanning was performed at $300 \mathrm{~nm}$. Calibration curves for ET were nonlinear (second-degree polynomials), with $R>0.998$. For both mobile phases limits of detection (LOD) were 0.03 and limits of quantification (LOQ) $0.1 \mu \mathrm{g} \mathrm{spot}^{-1}$. Both methods were validated.
\end{abstract}

\section{Introduction}

Ethylhexyl triazone (ET, Figure 1) is an oil-soluble UVB filter $\left(\lambda_{\max }\right.$ in ethanol $\left.314 \mathrm{~nm}\right)$ manufactured by BASF under the trade mark Uvinul T150 and used in cosmetic formulation at concentrations up to $5 \%$. Due to its insolubility in water and affinity to the skin keratin, it is particularly suitable for water-resistant products. Its excellent photostability and high absorption coefficient make it a valuable ingredient when a high SPF (sun protection factor) value is required [1].

Ethylhexyl triazone was quantified in cosmetic product mainly by RP-HPLC [2-9], less frequently UPLC [9], or UV spectrophotometry [10]. HPLC is also the technique of choice in ET skin permeation studies in vitro [11-13] as well as in the analysis of environmental samples containing ET $[14,15]$. Liquid chromatography was usually performed on RP-18 $[2-4,7,9,11-14]$ or RP-8 $[5,15]$ stationary phases and coupled with UV [2-9, 11-14] or MS [15] detectors.

The objective of this study was to develop a simple and cost-effective method of analysis of ethylhexyl triazone in complex sunscreen preparations by normal-phase thin-layer chromatography followed by densitometry.

\section{Experimental}

2.1. Chemicals, Material and Solutions. Uvinul T150 (ethylhexyl triazone) was kindly donated by BASF. Cyclohexane, diethyl ether, acetone, ethyl acetate, toluene, isopropanol, and methanol were from Polskie Odczynniki Chemiczne (POCh), Poland. SPF 20 water-resistant sun-care lotion containing ethylhexyl triazone, avobenzone, and octocrylene (Sample A) was manufactured by DAX Cosmetics, Poland. SPF 30 sun-care moisturizing cream containing ethylhexyl triazone, diethylamino hydroxybenzoyl hexyl benzoate, and octyl methoxycinnamate (Sample B) was from Soraya, Poland. Both cosmetic products analyzed throughout this study were preserved with parabens.

Uvinul T150, $500 \mathrm{mg}$, was weighed accurately into 100 $\mathrm{mL}$ volumetric flask, dissolved in adequate amount of acetone and diluted to volume to give a stock solution of the concentration $5 \mathrm{mg} \mathrm{mL}^{-1}$. The stock solution of ET was diluted with acetone to prepare standard solutions $(0.1,0.2$, $0.4,0.6,0.8,1.0,1.2,1.4,1.6,1.8$, and $\left.2.0 \mu \mathrm{g} \mu \mathrm{L}^{-1}\right)$.

2.2. Sample Preparation. Sun-care products $(1000 \mathrm{mg})$ were weighed accurately into $100 \mathrm{~mL}$ volumetric flasks. Approx- 


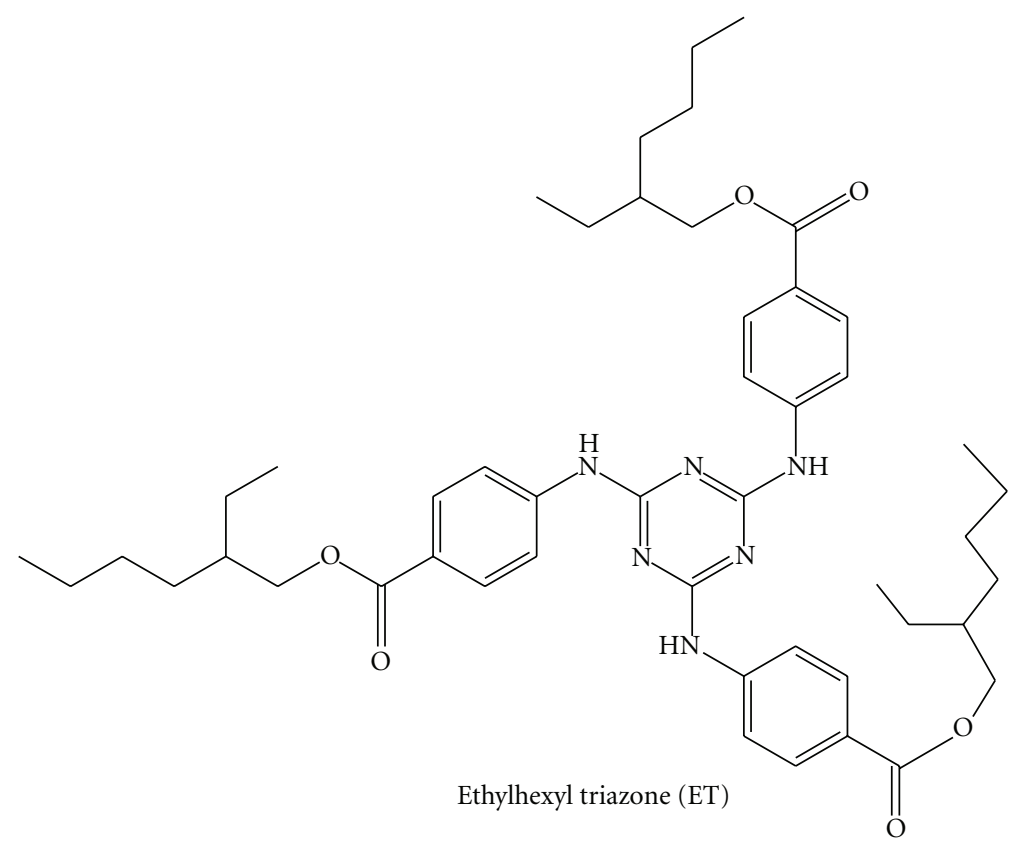

FIgURE 1: Structural formula of ET.

imately $70 \mathrm{~mL}$ methanol was added to each sample, and the flasks were vigorously shaken by use of a Premed (Poland) type 327 Universal Shaker for $60 \mathrm{~min}$. Methanol was then added to volume, and the flasks were wrapped with aluminum foil and left to stand for $60 \mathrm{~min}$.

2.3. Thin-Layer Chromatography. Thin-layer chromatography was performed on $10 \times 10 \mathrm{~cm} \mathrm{HP}$ quality silica gel 60 plates (layer thickness $0.2 \mathrm{~mm}$ ) from Merck or on $10 \times 20 \mathrm{~cm}$ standard quality silica gel 60 plates (layer thickness $0.25 \mathrm{~mm}$ ), also from Merck. Plates were spotted with the Desaga AS 30 sampler equipped with a $10 \mu \mathrm{L}$ syringe $\left(1 \mu \mathrm{Lspot}^{-1}\right), 15 \mathrm{~mm}$ from the bottom edge and at $8 \mathrm{~mm}$ intervals, starting $10 \mathrm{~mm}$ from the plate edge and developed with either cyclohexanediethyl ether 1:1(v/v), Method A, or cyclohexane-diethyl ether-acetone 15:1:2(v/v/v), Method B. Plates were developed in a vertical chromatographic chamber lined with filter paper and previously saturated with the appropriate mobile phase vapor for $20 \mathrm{~min}$. Development distance was $75 \mathrm{~mm}$ from the plate bottom edge. After development, plates were dried at room temperature $\left(20^{\circ} \mathrm{C}\right)$, scanned, and analyzed in reflectance mode with the Desaga CD 60 densitometer at $300 \mathrm{~nm}$.

2.4. Analysis of Ethylhexyl Triazone in Sunscreen Creams or Lotions. The sunscreen products solutions in methanol, prepared as described above, were spotted on silica gel $60 \mathrm{HP}$ TLC plates $(2 \mu \mathrm{L})$. The plates were then chromatographed as described above for ET standards (Section 2.3).

\section{Results and Discussion}

3.1. Method Development. The sun-care preparations analyzed in this study contained, apart from ET, other UV filters, that is, avobenzone (AVO) and octocrylene (OCR) (Sample A) or octyl methoxycinnamate (OMC) and diethylamino hydroxybenzoyl hexyl benzoate (DHHB) (Sample B), and preservatives absorbing within the UV range (parabens). In the course of our earlier research [16-18], three stationary phases (silicagel 60, RP-2 and RP-18) and several mobile phases were investigated. ET is a relatively lipophilic compound with strong affinity to RP-18 stationary phase [1618]. On the other hand, its separation from AVO, OCR, OMC, and DHHB on RP-2 stationary phase is poor [16]. For these reasons, it was decided that silica gel 60 is the stationary phase of choice. Mobile phases capable of effective ET separation from other UV filters listed above included cyclohexane-diethyl ether $1: 1(\mathrm{v} / \mathrm{v})$, cyclohexanediethyl ether-isopropanol 15:1:1 (v/v/v), toluene-ethyl acetate $15: 1$, and cyclohexane-diethyl ether-acetone $15: 1: 2$ $(\mathrm{v} / \mathrm{v} / \mathrm{v})$ [16-18]. An additional requirement was, however, that ET and sunscreens such as AVO and OCR (Sample A) or OMC and DHHB (Sample B) should be separated by one chromatographic procedure prior to their simultaneous densitometric quantification. This was achieved in the case of Sample B with mobile phase cyclohexane-diethyl etheracetone 15:1:2(v/v/v) on silica gel 60 [18] (Method B). In the case of Sample A, separation of ET from AVO and OCR was also successful (silica gel 60, cyclohexane-diethyl ether $1: 1(\mathrm{v} / \mathrm{v})$, Method A), but simultaneous quantification of AVO and OCR required a different approach because these sunscreens coelute under most conditions $[16,17]$. Both mobile phases gave ET spots of sufficient quality for densitometric analysis, although in the case of mobile phase $B$ the spots were of slightly better quality.

Analytical wavelength suitable for ET analysis $(300 \mathrm{~nm})$ was selected on the basis of multiwavelength scans obtained for this sunscreen. 


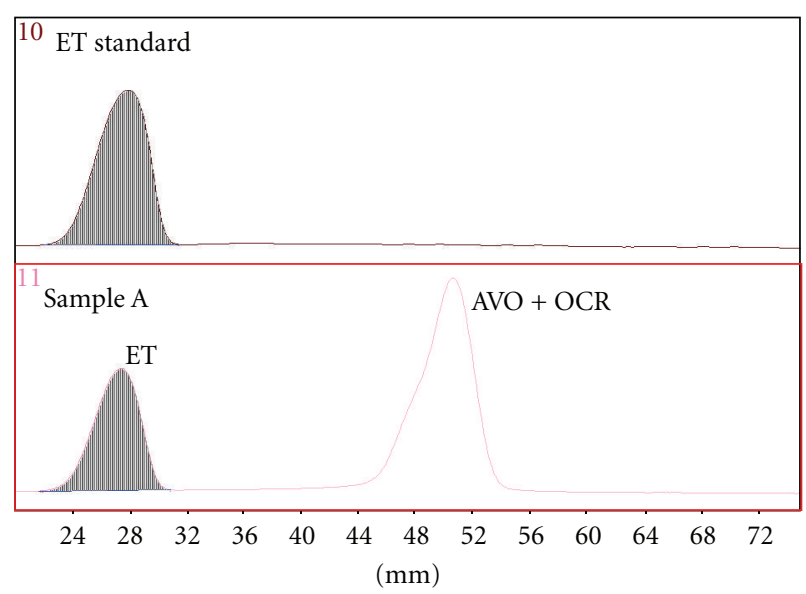

Figure 2: Densitograms of Sample A and ET standard (300 nm), Method A.

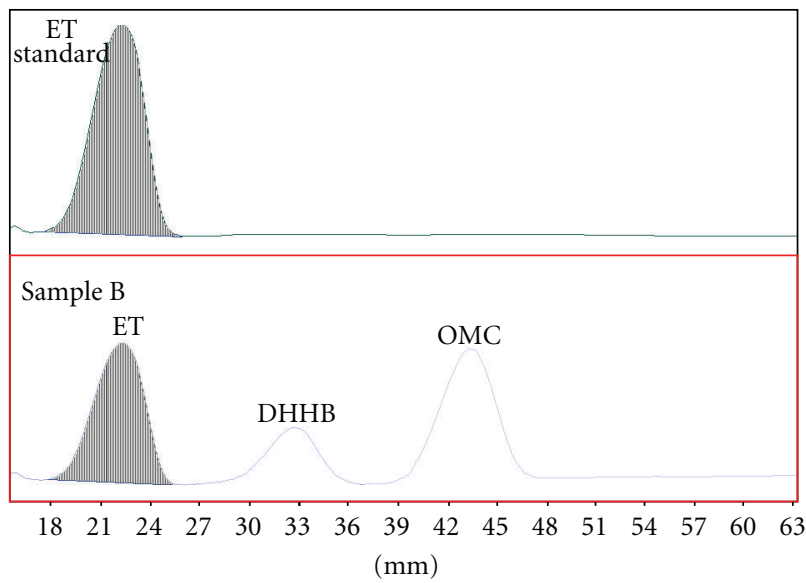

Figure 3: Densitograms of Sample B and ET standard (300 nm), Method B.

Typical densitograms of ET separated by Methods A and $\mathrm{B}$ are presented in Figures 2 and 3.

\subsection{Method Validation}

3.2.1. Specificity. Sun-care preparations analyzed throughout this study contained, apart from ET, other ingredients absorbing within the UV range such as OCR, AVO, DHHB, $\mathrm{OMC}$, and parabens. $R_{f}$ values for compounds of interest are as follows:

(i) mobile phase A: $R_{f}(\mathrm{ET}) 0.20, R_{f}(\mathrm{AVO}) 0.55, R_{f}$ (OCR) 0.60, $R_{f}$ (ethylparaben) 0.30, $R_{f}$ (OMC) 0.53, $R_{f}$ (DHHB) $0.37[16,17]$;

(ii) mobile phase B: $R_{f}(\mathrm{ET}) 0.10, R_{f}(\mathrm{AVO}) 0.42, R_{f}$ (OCR) $0.44, R_{f}$ (ethylparaben) $0.15, R_{f}$ (OMC) 0.47, $R_{f}(\mathrm{DHHB}) 0.30[16,18]$.

Chromatographic conditions A and B are suitable for separation of ET from UV filters listed above and, according

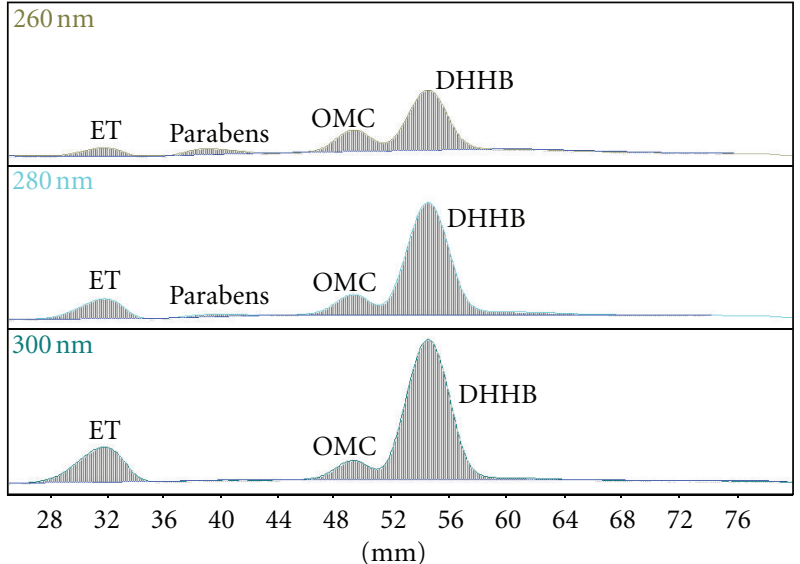

Figure 4: Multiwavelength scans of Sample B (260-300 nm), cyclohexane-diethyl ether-isopropanol 15:1:1 (v/v/v).

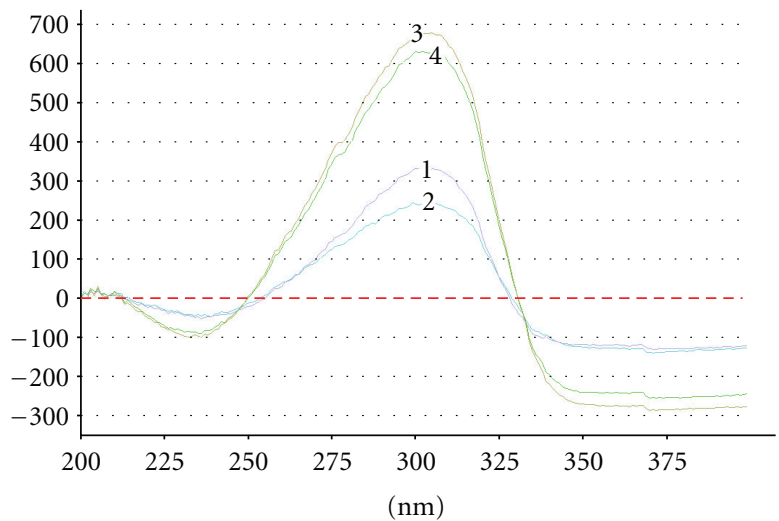

Figure 5: UV spectra of ET isolated from Sample A $(1,2,3)$ and of ET standard (4).

to our earlier studies [16], from the majority of other sunscreens used in contemporary sun-care preparations. The efficiency of Method B is slightly lower since the separation of ET from parabens is incomplete $\left(R_{f}\right.$ values for ET and ethylparaben are 0.10 and 0.15 , resp.); this is, however, not a problem, since the analytical wavelength for ET is $300 \mathrm{~nm}$ (Section 3.1.), and, as it can be seen in Figure 4, parabens do not absorb at $300 \mathrm{~nm}$.

Purity of ET peaks obtained during the analysis of Sample A was confirmed by UV/VIS spectra of sunscreens acquired directly from chromatographic plates in reflectance mode. Spectra collected at three different points of particular peaks obtained for the sample solution were compared with spectra acquired for the standard (Figure 5).

3.2.2. Calibration. Calibration plots for Methods A and B were obtained by plotting peak areas against amount of ET in the range $0.1-2.0 \mu \mathrm{g} \mathrm{spot}^{-1}$. In both cases linear regression coefficients were relatively high $(R=0.9905$ and 0.9851 , 
TABle 1: Calibration plots for ET: Methods A and B, automatic spotting, $300 \mathrm{~nm}$.

\begin{tabular}{lcc}
\hline & Method A & Method B \\
\hline Equation & $y=-640.2 x^{2}+3656.8 x+469.0$ & $y=-474.72 x^{2}+2384.8 x+463.0$ \\
$R$ & 0.9993 & 0.9983 \\
LOD & 0.03 & 0.03 \\
{$\left[\mu \mathrm{g} \mathrm{spot}^{-1}\right]$} & & 0.1 \\
$\mathrm{LOQ}$ & 0.1 & 0.1 \\
{$\left[\mu \mathrm{g} \mathrm{spot}^{-1}\right]$} & & \\
\hline
\end{tabular}

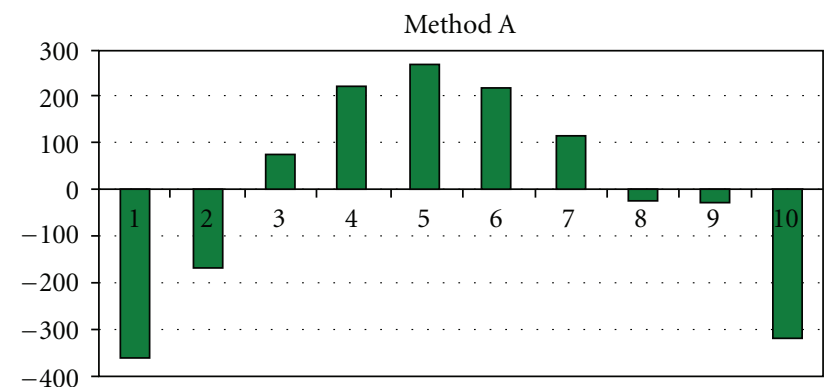

(a)

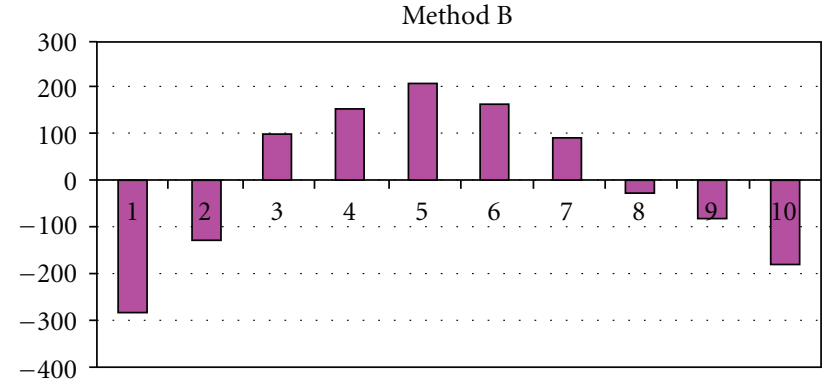

(b)

Figure 6: Residues test for calibration plots $\mathrm{A}$ and $\mathrm{B}$, linear regression. Method A: $y=2341.5 x+874.84, R=0.9905$. Method B: $y=1409.5 x+763.97, R=0.9851$.

resp.) but since this should not be used as the sole proof of linearity, nonnumerical analysis of residues according to [19] was performed. Residues (differences between experimental values and those calculated on the basis of appropriate equations) for linear calibration plots proposed for methods $\mathrm{A}$ and $\mathrm{B}$ showed strong tendencies which suggested that linear fit is inappropriate (Figure 6). Two possibilities were considered at this stage: selecting a narrower, pseudolinear range or using a different type of equation. Calibration plots were finally generated in the form of second-degree polynomials (Table 1), and their quality was assessed again by means of $R$ values and non-numerical analysis of residues (Figure 7). Residues plots for quadratic calibrations A and B (Figure 7) showed the lack of tendency that combined with very high $R$ values confirmed the correctness of curves fitting. It should be mentioned in this point that densitometric detection in Methods A and B was performed in reflectance

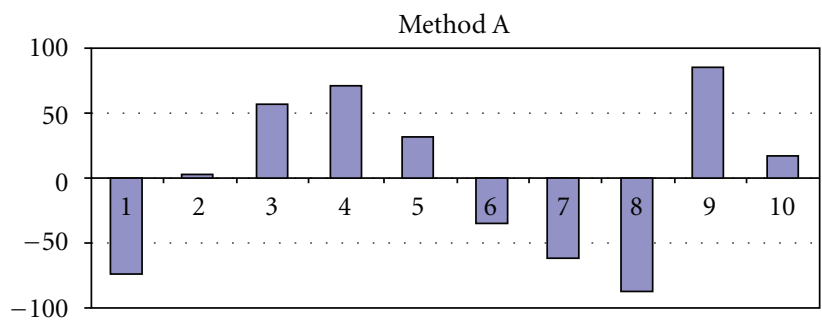

(a)

Method B

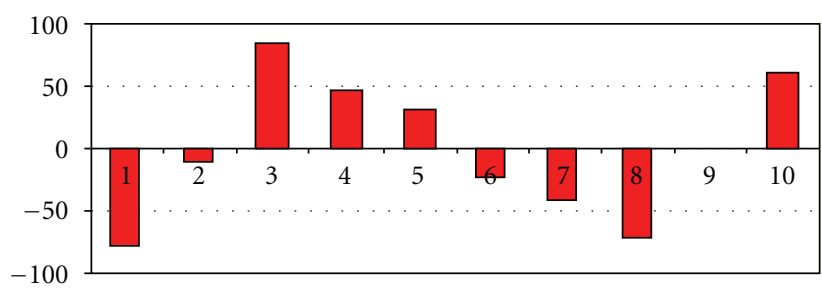

(b)

Figure 7: Residues test for calibration plots A and B, second-degree polynomials (equation according to Table 1).

mode. Lambert-Beer's law cannot be applied to diffuse reflectance so calibration in TLC/densitometry is seldom perfectly linear [19]; if this is the case, quadratic equations are often used [19].

3.2.3. Precision. Repeatability of the method was tested according to [19-21] by replicating the entire method on the same day, using the same cosmetic preparations, batches of solvents, and chromatographic plates, by the same analyst (Day 1, Analysis I and II). Intermediate precision was verified according to [19-21] by repeating the procedure on the same cosmetic preparations but on a different day, by a different analyst, using other batches of solvents and chromatographic plates (Day 2). The results of these experiments (Table 2) prove that the methods' precision is sufficient for routine product analysis.

3.2.4. Limits of Detection and Quantification. The limits of detection and quantification for ET determined experimentally on the basis of signal-to-noise ratio according to [22] are given in Table 1. 
TABLE 2: Results of repeatability, intermediate precision, and robustness tests.

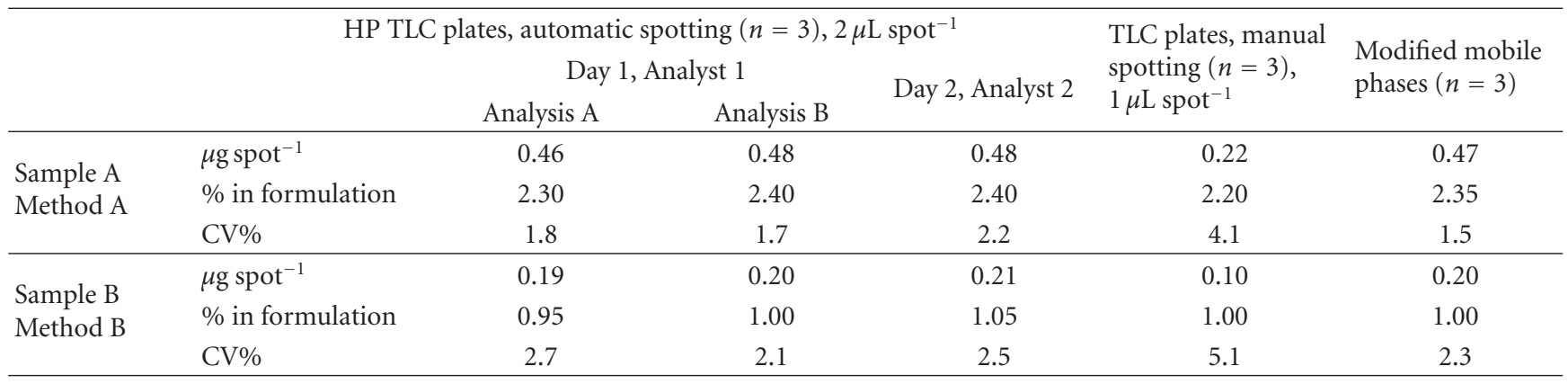

3.2.5. Robustness. After due consideration of factors that can influence the analysis results, it was concluded that the critical points are the quality of chromatographic plates (HPTLC versus TLC) and the method of spotting. The same cosmetic preparations were analyzed on HPTLC silica gel 60 chromatographic plates with automatic spotting and on standard TLC silica gel 60 plates with manual spotting with a microsyringe. The results of these analyses (Table 2) are similar, but coefficients of variations are slightly higher for manual spotting.

Additionally, the influence of small, deliberate changes in the mobile phase compositions on the results of ET quantification was tested:

Method A: cyclohexane-diethyl ether 0.9:1.1 (v/v)

Method B: cyclohexane-diethyl ether-acetone 15: $0.9: 2.1(\mathrm{v} / \mathrm{v} / \mathrm{v})$.

The results of these changes are summarized in Table 2.

3.2.6. Accuracy. Blank cosmetic creams were spiked with ET, AVO, and OCR (A) or ET, OMC and DHHB (B) at three concentrations 1,3 , and $5 \%(\mathrm{w} / \mathrm{w})$ of each sunscreen corresponding to $0.2,0.6$, and $1.0 \mu \mathrm{g} \mathrm{spot}^{-1}\left(2 \mu \mathrm{L} \mathrm{spot}^{-1}\right.$ of the cream solution prepared according to Section 2.2.). The analytical procedures A and B described in Section 2 were performed on the samples, and the recoveries are presented in Table 3.

3.2.7. Storage and Stability of Standard Solutions. Standard solutions of ET as well as solutions of other sunscreens and preservatives used in this investigation were refrigerated between the experiments and not exposed to light except for time needed for plate spotting. The stability of all solutions was in these conditions excellent as tested by UV/VIS spectroscopy over the period of 2 weeks.

\section{Conclusions}

Ethylhexyl triazone may be quickly and effectively separated from other oil-soluble UV filters and preservatives by normal-phase HPTLC on silica gel 60. Separation can be achieved by a variety of mobile phases, of which two, cyclohexane-diethyl ether $1: 1(\mathrm{v} / \mathrm{v})$ or cyclohexane-diethyl ether-acetone 15:1:2(v/v/v), were found superior. The
TABLE 3: Recovery tests $(n=3), 2 \mu \mathrm{L}$ spot $^{-1}$.

\begin{tabular}{llcc}
\hline $\begin{array}{l}\text { \% in } \\
\text { formulation } \\
(\mathrm{w} / \mathrm{w})\end{array}$ & & Method A & Method B \\
\hline \multirow{3}{*}{1.0} & Found (\%) & 0.95 & 1.00 \\
& \% recovery & 95.0 & 100.0 \\
& CV\% & 5.0 & 4.3 \\
\hline \multirow{3}{*}{3.0} & Found (\%) & 3.15 & 2.90 \\
& \% recovery & 105.0 & 96.7 \\
& CV\% & 4.9 & 3.9 \\
\hline \multirow{3}{*}{5.0} & Found (\%) & 4.80 & 5.10 \\
& \% recovery & 96.0 & 102.0 \\
& CV\% & 4.5 & 4.2 \\
\hline
\end{tabular}

methods of ethylhexyl triazone separation and quantification presented in this paper are based on one of the cheapest stationary phases (silica gel 60 , compared e.g., to RP-18 or RP-8 layers) and do not require toxic solvents. The analyses may be performed with analytical-grade solvents (HPLC purity solvents are not required), and, although HPTLC plates and automatic spotting are preferred, relatively good results may be achieved on standard-quality TLC plates spotted with a microsyringe. Fast, reliable and cost-effective densitometric quantification of ET proposed in this paper may, therefore, be recommended for routine analysis of cosmetic products.

\section{Acknowledgments}

This work was supported by an internal grant from the Medical University of Lodz, Poland (no. 503/3-016-03)50301. Thanks are due to BASF for free samples of Uvinul T150 used through this investigation.

\section{References}

[1] Uvinul grades, UV absorbers for cosmetic products, BASF technical information.

[2] D. J. Schakel, D. Kalsbeek, and K. Boer, "Determination of sixteen UV filters in suncare formulations by high-performance liquid chromatography," Journal of Chromatography A, vol. 1049, no. 1-2, pp. 127-130, 2004. 
[3] A. Salvador and A. Chisvert, "An environmentally friendly ("green") reversed-phase liquid chromatography method for UV filters determination in cosmetics," Analytica Chimica Acta, vol. 537, no. 1-2, pp. 15-24, 2005.

[4] M. Nyeborg, M. Pissavini, Y. Lemasson, and O. Doucet, "Validation of HPLC method for the simultaneous and quantitative determination of 12 UV-filters in cosmetics," International Journal of Cosmetic Science, vol. 32, no. 1, pp. 47-53, 2010.

[5] D. De Orsi, G. Giannini, L. Gagliardi et al., "Simple extraction and HPLC determination of UV-A and UV-B filters in sunscreen products," Chromatographia, vol. 64, no. 9-10, pp. 509515, 2006.

[6] S. C. Rastogi and G. H. Jensen, "Identification of UV filters in sunscreen products by high-performance liquid chromatography-diode-array detection," Journal of Chromatography A, vol. 828, no. 1-2, pp. 311-316, 1998.

[7] Dionex Application Brief 113, http://www.dionex.com.

[8] M. Herpol-Borrhmans and M. O. Masse, "Dosage de l'octyl triazone dans les produits cosmétiques solaires," International Journal of Cosmetic Science, vol. 14, no. 3, pp. 113-119, 1992.

[9] S. M. Lee, H. J. Jeong, and I. S. Chang, "Determination and validation of six sunscreen agents in suncare products by UPLC and HPLC," Journal of Cosmetic Science, vol. 59, no. 6, pp. 469-480, 2008.

[10] A. Tachev, "Development and validation of a spectrophotometric method for the determination of octyl triazone in sun protection cosmetic products, separately or in combination with the physical ultraviolet (UV) filters zinc oxide and titanium dioxide," Medical Review, vol. 41, no. 3, pp. 9-14, 2009.

[11] D. Monti, I. Brini, S. Tampucci et al., "Skin permeation and distribution of two sunscreens: a comparison between reconstituted human skin and hairless rat skin," Skin Pharmacology and Physiology, vol. 21, no. 6, pp. 318-325, 2008.

[12] G. Potard, C. Laugel, H. Schaefer, and J. P. Marty, "The stripping technique: in vitro absorption and penetration of five UV filters on excised fresh human skin," Skin Pharmacology and Applied Skin Physiology, vol. 13, no. 6, pp. 336-344, 2000.

[13] G. Potard, C. Laugel, A. Baillet, H. Schaefer, and J. P. Marty, "Quantitative HPLC analysis of sunscreens and caffeine during in vitro percutaneous penetration studies," International Journal of Pharmaceutics, vol. 189, no. 2, pp. 249-260, 1999.

[14] C. Plagellat, T. Kupper, R. Furrer, L. F. De Alencastro, D. Grand-jean, and J. Tarradellas, "Concentrations and specific loads of UV filters in sewage sludge originating from a monitoring network in Switzerland," Chemosphere, vol. 62, no. 6, pp. 915-925, 2006.

[15] R. Rodil, S. Schrader, and M. Moeder, "Pressurised membrane-assisted liquid extraction of UV filters from sludge," Journal of Chromatography A, vol. 1216, no. 51, pp. 8851-8858, 2009.

[16] A. W. Sobanska and E. Brzezinska, "Strategies of sunscreen separation by thin layer chromatography," Acta Poloniae Pharmaceutica. In press.

[17] A. W. Sobanska and E. Brzezinska, "Normal-phase TLC analysis of UV filters avobenzone and octocrylene in sunscreen preparations," Journal of Planar Chromatography, vol. 24, no. 2, pp. 154-159, 2011.

[18] A. Sobanska and E. Brzezinska, "Simultaneous NP TLC analysis of the sunscreens diethylamino hydroxybenzoyl hexyl benzoate and octyl methoxycinnamate," Journal of Planar Chromatography, vol. 24, no. 3, pp. 227-231, 2011.
[19] K. Ferenczi-Fodor, B. Renger, and Z. Végh, "The frustrated reviewer-Recurrent failures in manuscripts describing validation of quantitative TLC/HPTLC procedures for analysis of pharmaceuticals," Journal of Planar Chromatography, vol. 23, no. 3, pp. 173-179, 2010.

[20] ICH Harmonised Tripartite Guideline: Validation of Analytical procedures: Test and Methodology, Q2 (R1), Geneva, Switzerland, 2005, http://www.ich.org.

[21] J. Ermer and J. H. M. Miller, Method Validation in Pharmaceutical Analysis. A Guide to Best Practice, Wiley-VCH, Weinheim, Germany, 2005.

[22] P. Konieczko and J. Namiesnik, Ocena i Kontrola Jakości Wyników Pomiarów Analitycznych (Evaluation and Quality Control of Analytical Results, in Polish), Wydawnictwo NaukowoTechniczne, Warszawa, Poland, 2007. 


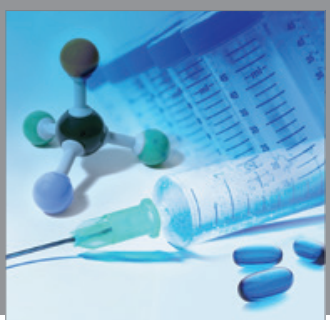

International Journal of

Medicinal Chemistry

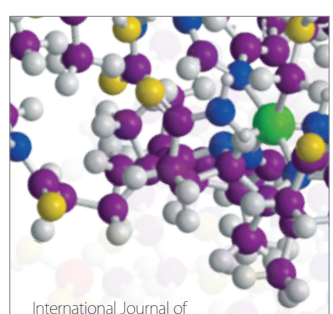

Carbohydrate Chemistry

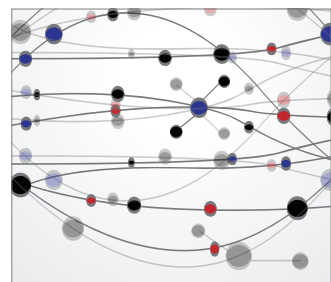

The Scientific World Journal
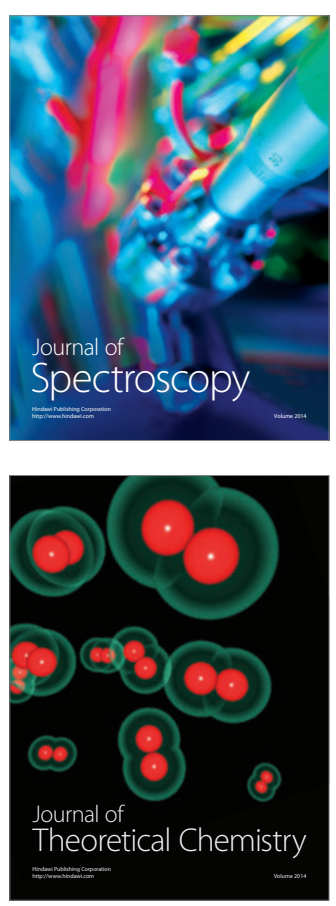
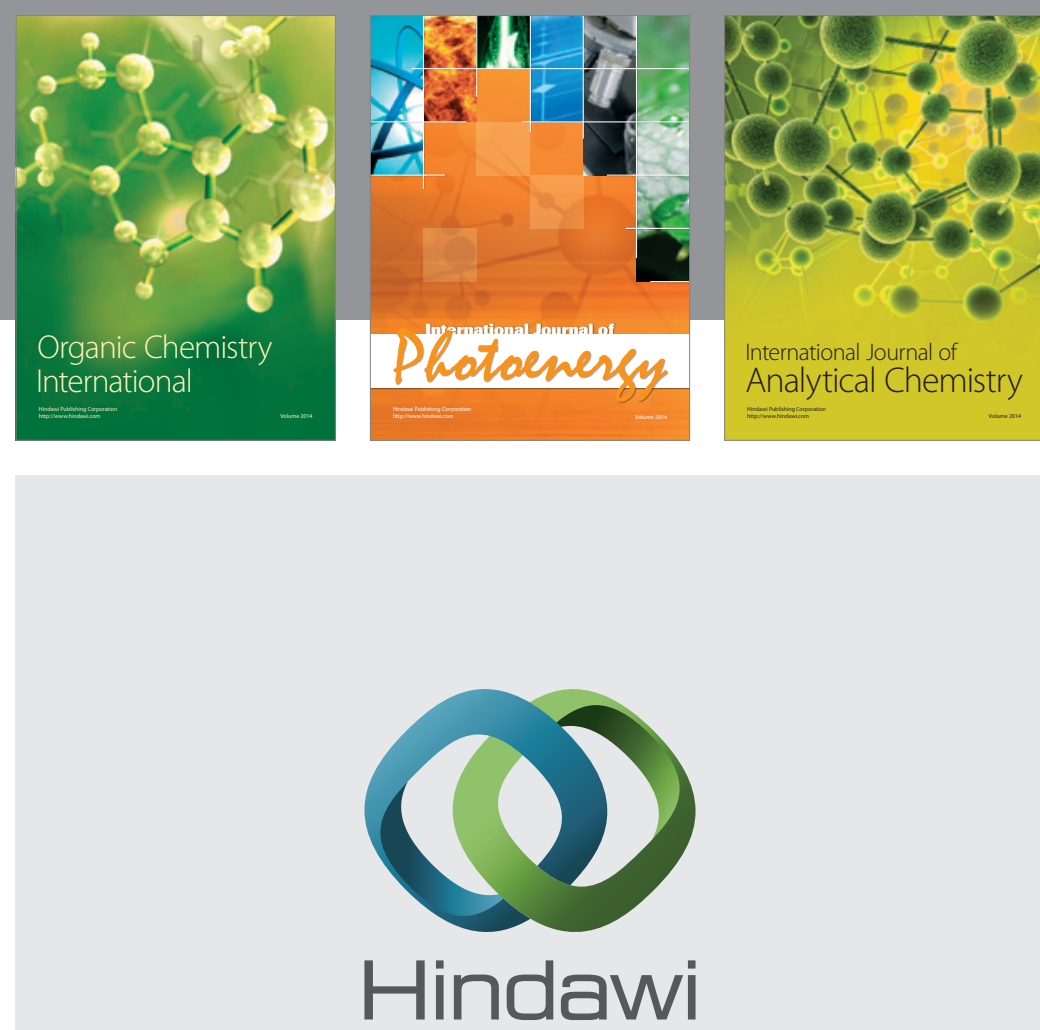

Submit your manuscripts at

http://www.hindawi.com
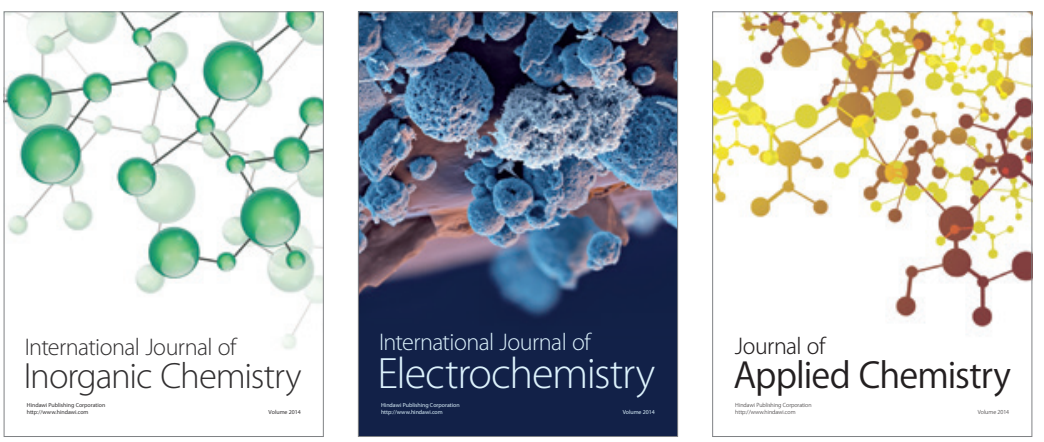

Journal of

Applied Chemistry
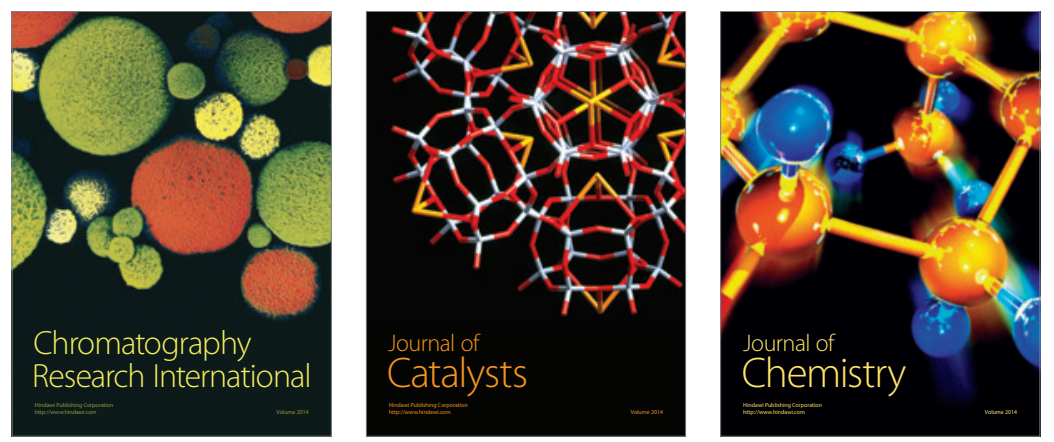
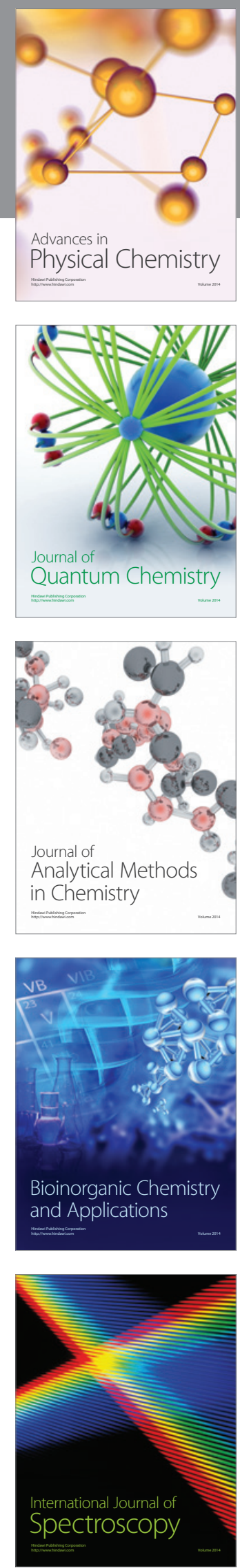